\title{
Pengaruh Model Pembelajaran Discovery Learning terhadap Kemampuan Berpikir Logis Siswa Kelas X MIA SMA Muhammadiyah 1 SurakartaTahun Pelajaran 2013/ 2014
}

\author{
The Effect of Discovery Learning on Students' Logical Thinking Skills \\ of Grade X MIA SMA Muhammadiyah 1 SurakartaAcademic Year 2013/2014 \\ Marina Rizki Tri Cahyani ${ }^{\text {a }}$, Sri Dwiastuti ${ }^{\mathbf{b}}$, Maridi
${ }^{\text {c }}$
a Pendidikan Biologi FKIP UNS, Email: teccemarr@ yahoo.com
${ }^{\mathrm{b}}$ Pendidikan Biologi FKIP UNS, Email: dwiastuti54@ gmail.com
${ }^{\mathrm{c}}$ Pendidikan Biologi FKIP UNS, Email: maridi_uns@ yahoo.co.id
}

Diterima 15 Agustus 2014, disetujui 17 September 2014

\begin{abstract}
The purpose of the research was to determine effect of Discovery Learning on student's logical thinking skills of grade X MIA SMA Muhammadiyah 1 Surakarta academic year 2013/2014. The study was a quasi experimental research with a Posttest Only Nonequivalent Control Group Design. The population was all students of class X MIA SMA Muhammadiyah 1 Surakarta in the school year 2013/2014. The sampling technique was cluster sampling. Data collection techniques using tests and non-test methods. Independent sample t-test was used to test hypothesis. The result of hypothesis testing has a significance of 0.048 . The average value of logical thinking test on control class was 4.41 and the experimental class was 5.19. The conclusion was Discovery Learning significant effect on student's logical thinking skills of grade X MIA SMA Muhammadiyah 1 Surakarta academic year 2013/2014.
\end{abstract}

Key Words: Discovery Learning, logical thinking skills, conventional learning

\section{Pendahuluan}

Pembelajaran pada kurikulum 2013 diharapkan dapat menuntun siswa untuk mencari tahu dan menekankan berpikir logis. Pembelajaran meliputi kegiatan pengamatan, pertanyaan, pengumpulan data, penalaran, dan penyajian hasilnya melalui pemanfaatan berbagai sumber belajar (Kemendikbud, 2013).

Penalaran tingkat tinggi atau cara berpikir logis yang tinggi diperlukan agar siswa dapat menjawab pertanyaan dalam hal pemecahan masalah, berpikir kritis, serta berpikir kreatif. Berpikir logis yang tinggi sangat diperlukan oleh siswa dalam proses pembelajaran di kelas khususnya dalam menjawab pertanyaan karena siswa perlu menggunakan pengetahuan, pemahaman, dan keterampilan yang dimilikinya dan menghubungkannya dalam situasi baru (Rofiah, Aminah, \& Ekawati, 2013).

Berdasarkan tahap perkembangan berpikir logis, siswa SMA berada pada tahap penalaran formal yaitu tahapan tertinggi dalam kemampuan berpikir logis. Piaget (1958) menyatakan bahwa anak-anak yang berusia lebih dari 11 tahun berada dalam tahap berpikir formal yaitu berpikir secara abstrak. 
Beberapa penelitian menunjukkan masih rendahnya kemampuan berpikir logis siswa SMA. Refleksi dari hasil PISA (Programme for International Students Assessment) pada tahun 2009 terhadap pembelajaran sains menunjukkan bahwa sebagian besar siswa Indonesia menguasai pelajaran sampai level tiga, dengan kata lain kemampuan bernalar siswa Indonesia masih rendah jika dibandingkan dengan negara lain (Kemendikbud, 2013).

Rendahnya kemampuan berpikir logis pada siswa dapat dikaitkan dengan sistem pendidikan yang umumnya hanya berorientasi pada nilai ujian, oleh karena itu siswa kurang menggunakan kemampuan berpikirnya. Pembelajaran sains yang dilaksanakan hanya untuk memenuhi syarat materi yang sudah ditetapkan dalam silabus beserta alokasi pembelajarannya tanpa memberi kesempatan siswa untuk melakukan investigasi (penyelidikan) untuk melatih kemampuan berpikir siswa. Anwar dan Abbas (Fah, 2009) melaporkan bahwa sistem evaluasi pembelajaran sains yang dilakukan tidak menekankan porsi yang sama antara proses dengan produk sains. Hampir $100 \%$ sistem penilaian capaian belajar sains hanya fokus terhadap aspek produk sehingga dapat dipastikan bahwa siswa yang hasil belajarnya baik adalah siswa yang dapat menjelaskan konsep dan teori serta menyelesaikan permasalahan yang sama dengan rumus (formula) yang sudah tersedia.

Keadaan seperti yang dipaparkan di atas juga terjadi di SMA Muhammadiyah 1 Surakarta, khususnya di kelas X MIA (Matematika dan Ilmu Alam). Siswa kurang diberi kesempatan untuk melakukan kegiatan penyelidikan yang dapat melatih kemampuan berpikir atau bernalar sehingga menyebabkan rendahnya kemampuan berpikir logis siswa.

Kemampuan berpikir logis memerlukan kegiatan penyelidikan (Fios, 2013). Salah satu model pembelajaran yang menghadirkan kegiatan penyelidikan yaitu Discovery Learning. Discovery Learning arau belajar penemuan memerlukan pengajuan pertanyaan, permasalahan, atau situasi yang membingungkan untuk diselesaikan sehingga menjadi dorongan bagi para siswa untuk membuat tebakan-tebakan jawaban yang intuitif jika mereka tidak yakin (Schunk, 2012). Discovery Learning mengacu pada penguasaan pengetahuan untuk diri sendiri yang diperoleh melalui proses mencari, mengolah, menelusuri, dan menyelidiki. Model pembelajaran penemuan berdasar pada prinsip metode ilmiah sehingga dapat melatih siswa bekerja secara sistematis untuk menemukan pengetahuan baru maupun 
untuk menyelesaikan permasalahan sehingga model pembelajaran penemuan dapat melatih kemampuan bernalar siswa.

Berdasarkan kelebihan yang dimiliki oleh model pembelajaran Discovery learning, maka perlu dilakukan penelitian untuk mengetahui pengaruh Discovery learning terhadap kemampuan berpikir logis siswa kelas X MIA SMA Muhammadiyah 1 Surakarta tahun pelajaran 2013/2014.

\section{Metode Penelitian}

Penelitian dilaksanakan di kelas X MIA SMA Muhammadiyah 1 Surakarta tahun pelajaran 2013/2014 pada semester genap. Penelitian termasuk dalam penelitian kuantitatif yang bersifat eksperimen semu (quasi experimental research). Penelitian menggunakan desain penelitian Post-test Only Control Design with Nonequivalent Group Design. Satu kelas dipilih sebagai kelas kontrol dan satu kelas yang lain dipilih sebagai kelas eksperimen dari ketiga kelas MIA yang ada. Model Discovery Learning diterapkan pada kelas eksperimen.

Populasi yang digunakan dalam penelitian adalah seluruh siswa kelas $\mathrm{X}$ MIA SMA Muhammadiyah 1 Surakarta tahun pelajaran 2013/2014. Sampel yang digunakan dalam penelitian terdiri dari 2 kelompok atau kelas di kelas X MIA
SMA Muhammadiyah 1 Surakarta yaitu kelas X MIA 2 dengan jumlah siswa 32 orang sebagai kelas kontrol dan kelas $\mathrm{X}$ MIA 1 dengan jumlah siswa 32 orang sebagai kelas eksperimen. Teknik pengambilan sampel menggunakan cluster sampling.

Variabel bebas dalam penelitian yaitu model pembelajaran Discovery Learning sedangkan variabel terikat yaitu kemampuan berpikir logis siswa kelas $\mathrm{X}$ MIA SMA Muhammadiyah 1 Surakarta tahun pelajaran 2013/2014. Teknik pengumpulan data yang digunakan dalam penelitian yaitu metode tes dan non-tes. Tes berupa soal tertulis untuk mengukur kemampuan berpikir logis. Metode nontes berupa dokumentasi dan observasi. Instrumen penelitian yang disusun diuji validitas dan reliabilitasnya menggunakan program SPPS 16.

Uji prasyarat dilakukan sebelum menguji hipotesis. Uji prasyarat meliputi uji normalitas dan homogenitas. Uji normalitas menggunakan uji Kolmogorov-Smirnov. Uji homogenitas menggunakan uji Levene's. Uji hipotesis yang digunakan adalah uji hipotesis komparatif dua sampel yang independen dengan uji-t. Uji normalitas, homogenitas, dan hipotesis dilakukan menggunakan bantuan program SPSS 16.

\section{Hasil dan Pembahasan}


Rincian nilai pada kelas kontrol yaitu sejumlah 4 siswa memeroleh nilai 2, 6 siswa memeroleh nilai 3,7 siswa memeroleh nilai 4, 7 siswa memeroleh nilai 5, 5 siswa memeroleh nilai 6,2 siswa memeroleh nilai 7 , dan 1 siswa memeroleh nilai 8. Rincian nilai pada kelas eksperimen yaitu sejumlah 1 siswa memeroleh nilai 2, 4 siswa memeroleh nilai 3, 5 siswa memeroleh nilai 4,8 siswa memeroleh nilai 5,8 siswa memeroleh nilai 6, 4 siswa memeroleh nilai 7, dan 2 siswa memeroleh nilai 8 . Distribusi dan deskripsi data kemampuan berpikir logis dapat dilihat pada Tabel 1 .

Hasil uji hipotesis menggunakan uji-t menunjukkan bahwa nilai kemampuan berpikir kelas kontrol dan eksperimen berbeda nyata. Nilai kemampuan berpikir logis yang berbeda nyata dapat dilihat melalui perbandingan rata-rata nilai kelas kontrol dan eksperimen. Rata-rata nilai kelas eksperimen lebih tinggi daripada rata-rata nilai kelas kontrol. Kelas eksperimen memiliki rata-rata nilai sebesar 5,19 sedangkan kelas kontrol memiliki ratarata nilai sebesar 4,41. Histogram perbandingan nilai rata-rata kemampuan berpikir logis siswa kelas kontrol dan eksperimen dapat dilihat pada gambar 1.

Sejumlah $31,25 \%$ atau 10 siswa pada kelas kontrol memiliki kemampuan berpikir logis tingkat transisi dan 22 siswa atau $68,75 \%$ siswa yang sudah mencapai kemampuan berpikir logis tingkat formal (berpikir abstrak), sedangkan sebanyak 5 siswa atau 15,63\% siswa pada kelas eksperimen memiliki kemampuan berpikir logis tingkat transisi dan 27 siswa atau 84,38\% sudah berada dalam tingkat berpikir formal/abstrak.

Perbedaan rata-rata nilai tes kemampuan berpikir logis antara kelas kontrol dan eksperimen dipengaruhi oleh adanya perbedaan model pembelajaran yang diterapkan pada kedua kelas tersebut. Kemampuan berpikir logis memerlukan kegiatan penyelidikan (Fios, 2013), salah satu model pembelajaran yang menghadirkan kegiatan penyelidikan yaitu Discovery Learning (belajar penemuan). Kemampuan berpikir logis juga dicapai melalui aktivitas bernalar. Discovery Learning melatih kemampuan bernalar siswa (Schunk, 2012). Model Discovery Learning diterapkan pada kelas eksperimen.

Pembelajaran menggunakan model Discovery Learning terlaksana dalam lima fase sesuai yang dinyatakan Veermans (2003). Kelima fase dalam Discovery Learning yaitu orientasi (orientation), menyusun hipotesis (hypothesis generation), menguji hipotesis (hypothesis testing), menyimpulkan (conclusion), dan konfirmasi (regulation). 
Saat orientasi, siswa membangun pemahaman awal dengan melibatlan informasi dan pengetahuan yang telah diperoleh sebelumnya. Guru memberikan simulasi dengan cara menampilkan fenomena/permasalahan yang terjadi di lingkungan sekitar. Pemberian simulasi bertujuan agar siswa dapat memberikan argumen/pendapat sebagai solusi untuk mengatasi permasalahan yang ditampilkan, kegiatan tersebut dapat melatih kemampuan berpikir logis karena suatu argumentasi disebut masuk akal jika pemikiran tersebut diperoleh berdasarkan proses berpikir yang tepat.

Pada fase hypothesis generation, siswa menyusun hipotesis atau jawaban sementara untuk menjawab suatu permasalahan. Fase perumusan hipotesis dapat melatih kemampuan berpikir logis siswa khususnya pada aspek combinatorial reasoning dan correlational reasoning karena kedua aspek tersebut tampak pada kegiatan perumusan hipotesis (Yenilmez, Sungur, \& Tekkaya, 2005).

Fase selanjutnya yaitu hypothesis testing, siswa merencanakan dan melakukan percobaan untuk menguji hipotesis. Pengujian hipotesis melatih kemampuan berpikir logis pada aspek controlling variables karena aspek tersebut diperlukan pada perencanaan, pelaksanaan, dan interpretasi (Yenilmez, et al., 2005).
Fase yang ke empat yaitu conclusion. Siswa menganalisis hasil percobaan dan mengaitkannya dengan hipotesis yang telah dibuat sehingga siswa dapat membuat suatu kesimpulan. Aspek-aspek yang terlibat dalam fase conclusion yaitu proportional reasoning, controlling variables, probabilistic reasoning, dan correlational reasoning. Aspek proportional reasoning dibutuhkan khususnya pada konstruksi serta interpretasi dari tabulasi data dan grafik. Probabilistic reasoning diperlukan dalam interpretasi data yang diperoleh dari hasil investigasi, observasi atau eksperimen. Correlational reasoning juga diperlukan dalam interpretasi data yang berkaitan dengan hubungan antarvariabel (Yenilmez, et al., 2005). Kegiatan interpretasi data dan grafik dilakukan siswa saat mengolah data untuk menghasilkan kesimpulan, seperti yang dikemukakan Nur (Tawil, dkk., 2009) bahwa penalaran probabilistik terjadi pada saat seseorang menggunakan informasi untuk memutuskan benar atau tidak benarnya suatu kesimpulan.

Fase terakhir model Discovery Learning yaitu regulation. Siswa bersama guru mereview hasil diskusi siswa kemudian guru mengadakan evaluasi agar siswa dan guru mengetahui ketercapaian tujuan pembelajaran pada suatu pertemuan. 
Tabel 1. Distribusi dan Deskripsi Data Kemampuan Berpikir Logis

\begin{tabular}{|c|c|c|}
\hline \multirow[b]{2}{*}{ Nilai } & \multicolumn{2}{|c|}{ Frekuensi } \\
\hline & $\begin{array}{c}\text { Kelompok } \\
\text { Kontrol }\end{array}$ & $\begin{array}{c}\text { Kelompok } \\
\text { Eksperimen }\end{array}$ \\
\hline 2 & 4 & 1 \\
\hline 3 & 6 & 4 \\
\hline 4 & 7 & 5 \\
\hline 5 & 7 & 8 \\
\hline 6 & 5 & 8 \\
\hline 7 & 2 & 4 \\
\hline 8 & 1 & 2 \\
\hline $\bar{\Sigma}$ & 32 & 32 \\
\hline Rata-rata & 4,41 & 5,19 \\
\hline $\begin{array}{l}\text { Nilai } \\
\text { maksimal }\end{array}$ & 8,00 & 8,00 \\
\hline $\begin{array}{l}\text { Nilai mini- } \\
\text { mal }\end{array}$ & 2,00 & 2,00 \\
\hline
\end{tabular}

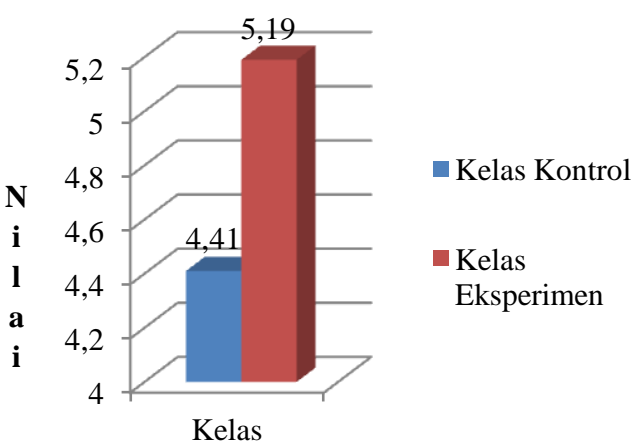

Gambar 1. Histogram Perbandingan Nilai Rata-rata Kemampuan Berpikir Logis Siswa Kelas Kontrol dan Eksperimen

\section{Simpulan}

Berdasarkan hasil penelitian dapat disimpulkan bahwa model pembelajaran Discovery Learning berpengaruh terhadap kemampuan berpikir logis siswa kelas X MIA SMA Muhammadiyah 1 Surakarta tahun pelajaran 2013/2014.

\section{Daftar Pustaka}

Fah, L. Y. (2009). Logical Thinking Abilities among Form 4 Students in the Interior Division of Sabah, Malaysia. Journal of Science and Mathematics Education in Southeast Asia , 32 (2), 161-187

Fios, F. (2013). Pengantar Filsafat: Ilmu dan Logika. Jakarta: Salemba Humanika

Inhelder, B., \& Piaget, J. (1958). The Growth of Logical Thinking: From Childhood to Adolescence. New York: Basic Books, Inc

Kemendikbud. (2013). Pengembangan Kurikulum 2013.

Rofiah, E., Aminah, N. S., dan Ekawati, E. Y. (2013). Penyusunan Instrumen Tes Kemampuan Berpikir Tingkat Tinggi Fisika pada Siswa SMP. Jurnal Pendidikan Fisika , I (2), 17

Schunk, D. H. (2012). Learning Theories: An Educational Perspective. New York: McGraw-Hill Companies

Tawil, M., Odja, A. H., \& Suryansari, K. (2009). Pengaruh Kemampuan Penalaran Formal dan Lingkungan Pendidikan Keluarga terhadap Hasil Belajar Fisika Siswa Kelas X SMA Negeri 1 Sungguminasa Kabupaten Gowa

Veermans, K.H. (2003).Intelligent Support for Discovery Learning. Ph.D.Thesis. Twente University Press.

Yenilmez, A., Sungur, S., \& Tekkaya, C. (2005). Investigating Student's Logical Thinking Abilities : The Effects of Gender and Grade Level. Jurnal Pendidikan Universitas Hacettepe, 28, 219-225 